\title{
Eleven
}

\section{THE BIOPIC TELEOLOGICAL ARGUMENT}

No appeal to infinitely many worlds, either antecedent or contemporary, can explain the existence and order of our life-supporting world unless infinitely many worlds actually exist. Likewise, God cannot explain our life-supporting world unless there actually is a God. Theistic Cosmology affirms that God caused the Big Bang, that God is THE necessary condition for its occurrence; but this claim is true only if God exists. What reasons support the belief that God exists?

Rational evidence for God was expressed traditionally in philosophical arguments for God's existence. Two traditional arguments for God, the Teleological and the Cosmological, are of special interest to us because they directly invoke what we know about the cosmos.

When he considered evidences for God drawn from our knowledge of the world, the philosophical theologian John Hick concluded that "The universe, as presently accessible to us, is religiously ambiguous in that it is capable of being interpreted intellectually and experientially in both religious and naturalistic ways." Since all phenomena can be interpreted in both Theistic and Naturalistic terms, neither position can win a clear victory over the other, Hick contends. Yet, the crucial issue is not whether all observations can be interpreted in a certain way. Rather, it is whether one interpretation is more defensible rationally than another. Hick is too generous and kind toward Naturalism. We saw in Chapter Two that no strong case can be made for Naturalism, especially when measured by its own appeal to scientific method alone; and in the ensuing chapters we saw that contemporary atheistic cosmologists fail to explain adequately the origin, order, and existence of our universe without God.

Can a good case be made for God's existence based partly on the order or design of the universe disclosed to and through contemporary Anthropic or Biopic Cosmology? Granted that they will not be absolutely certain, can our inquiry produce theistic results that are rationally warranted and compelling?

\section{God's Purpose for the Universe and Cosmic Teleology}

The Teleological Argument or Argument from Design affirms that the observed order of the world provides powerful evidence both for the existence of God and for divine attributes like power, intelligence, and benevolence or good intentions. A well-designed cosmos implies not only that God exists but also something about what God is like. The Argument from Design expresses the deep religious intuition that the ultimate cause of the universe knew what it was doing and did it well from commendable motives. Perhaps no one ever really believes in God without that intuition, but reflection may make it plausible. 
From the time of Plato, innumerable versions of the Argument from Design have been offered, criticized, defended, and attacked. Today's Anthropic Cosmology presents us with dazzling indications that our world was deliberately designed by an intelligent and benevolent being of Divine proportions. Amazingly, most Anthropic Cosmologists reject a theistic explanation of the data and favor some version of an infinite world-ensemble metaphysics, according to which a life-supporting world like ours occasionally happens accidentally in a infinite number of tries. Barrow and Tipler acknowledge the possibility of a Theistic Anthropic Cosmology, but they and most other Anthropic Cosmologists reject it. Should we follow their lead?

A Biopic Teleological Argument for God contends that all of life, not just intelligent life, requires God. Is the Biopic Teleological Argument for God's existence defensible? Consider the following premises of a strong Biopic Teleological Argument for God.

Premise 1: Our universe is exceptionally fine-tuned for the production of an immense variety of intrinsically valuable complex forms of life.

Premise 2: This fine-tuning was caused by either by the existence of: A. infinitely many universes, or B. the Principle of Plenitude, or C. nothingness, or D. God-a transcendent, benevolent, Supercosmic Intellect.

Premise 3: It was not caused by the existence of: A. infinitely many universes, or B. the Principle of Plenitude, or C. nothingness.

Premise 4: Probabilities favor God.

Therefore: Our universe's fine-tuning for life was caused by an existing God, a transcendent, benevolent, Supercosmic Intellect.

Both Teleological and Cosmological Arguments for God reason from something that is known to be true of the world through sense experience to the existence of a transcendent Ultimate Reality who best accounts for that something. The Teleological Argument reasons from the presence of order, design, and purpose in the universe to the existence of a supreme, intelligent, skillful orderer or designer, and benevolent purposer-God. The Cosmological Argument, examined in Chapter Twelve, reasons from contingency or dependence in and of the world to the existence of a Divine ground for all contingency.

Teleological and Cosmological Arguments for God contain some empirical premises that are known to be true on the basis of observation and inductive inference; but scientists are usually not interested in these kinds of experiential truths. Other premises in the arguments are philosophical and must be defended philosophically, with no pretense of doing natural science. Philosophy can operate at a level of generality that goes beyond the natural sciences, even though the line separating them is not exact. Although not done in the Teleological Argument, philosophy can even appeal to other types of experience-intuitive, introspective, religious, mystical-to which natural science, confined to 
sense experience, cannot appeal. Philosophy's repertoire of arguments, concepts, and analysis transcends the natural sciences. Absolute certainty is not available to us anywhere, especially in philosophy and natural science. A fallibilistic approach to philosophy concedes from the outset that absolute certainties are unreachable, but it also eschews absolute skepticism. Without giving us absolute certainty, philosophy can at least give us rationally warranted assertions and an enlightened faith-something far superior to blind faith.

Now let us examine and defend the premises of our Biopic Teleological Argument more carefully.

\section{A. Extraordinary Cosmic Coincidences that Favor Life}

The first premise of the Biopic Teleological Argument points out that our universe is exceptionally well-designed for the production of an immense variety of intrinsically valuable complex forms of life, human and otherwise. Atheistic versions of the Anthropic Principle, discussed previously, agree that scientific cosmology has discovered impressive empirical evidence that our universe is extraordinarily fine-tuned to engender and sustain our existence. If it were not, we would not be here. But we are here! Why must we regard our universe as fine-tuned for life, and what best explains that?

Our universe is exceptionally suitable for the production of complex intrinsically valuable life during certain prolonged cosmic periods like the one in which we exist. Exceedingly small changes in the most basic physical features of our universe would make complex and valuable life impossible. About that, very little disagreement exists. Tiny changes, usually much less than one percent, in the numerical values of fundamental physical features of nature like gravity, electromagnetism, the strong nuclear force, and the weak force, would have resulted in a lifeless universe. So would minute changes in initial conditions, natural laws, and many other primary components of the cosmos. All the fundamental components of our cosmos, as well as their harmonious interrelationships, must be calibrated with incredible exactitude to produce a life-sustaining universe.

In what follows, most of the numbers are omitted; but physicists attach precise numbers to all the incredible life-supporting "coincidences" that make up the basic physics and chemistry of a life-supporting universe like our own. To the finite range of every numerical value essential for the production of a life-sustaining universe corresponds an infinity of numerical values that would insure lifelessness. For example, the speed of light at roughly 186,000 miles per second is a very fundamental constant in a relativity universe; but, as with all numerical values essential for life, a World-designer could get it wrong in an infinite number of ways. If the speed of light were $184,000,188,000$, or 189,000 miles per second, life would probably be impossible. An infinite number of ways to go wrong correlate with the very small range of permissible numbers 
for every physical condition that supports life. An infinite number of whole numbers above 186,000 miles per second, and an infinity of fractions between all these whole numbers, would yield lifeless universes.

Every possible lifeless universe would be an actual universe if all possible universes are actualized, as dictated by the Principle of Plenitude. This includes infinite variations on the numbers for all physical conditions that could enter into the constitution of possible universes. According to Stephen Hawking,

It seems clear that there are relatively few ranges of values for the numbers that would allow the development of any form of intelligent life. Most sets of values would give rise to universes that, although they might be very beautiful, would contain no one able to wonder at that beauty. ${ }^{2}$

Getting all the numbers right for life is a task for Infinite Intelligence. All the physical fundamentals of our universe and their collective harmony were precision-tuned for life production, and this is overwhelming evidence that our universe was deliberately contrived for life by a Divine Being who loves life. Consider just a few cosmic fundamentals that are specially designed for life.

\section{i. Matter/Antimatter Asymmetry}

Either broken matter/antimatter symmetry, or primordial asymmetry, is necessary for the emergence of valuable life. We really do not know whether symmetry prevailed in the beginning, or whether asymmetry was an original feature of our universe. Assuming broken symmetry, as do most cosmologists, the processes that upset the balance of matter and antimatter in the earliest universe are very mysterious; but if symmetry had not been broken, the universe would not have evolved beyond a primordial fireball fueled by endless matter-antimatter collisions and explosions. Astrophysicists believe that when symmetry was broken, only one material particle survived for every billion matter-antimatter pairs that were annihilated. Without these exceptionally rare survivors, there would be no stable baryonic matter (protons and neutrons) and leptonic matter (electrons and neutrinos). No stable physical world would exist at all, and if no stable physics, then no life. A universe of stable antimatter would serve just as well for life, but it too would require either broken symmetry or primordial asymmetry.

Symmetry might have snapped in an infinite variety of ways, very few of which would be life-supporting. It looks as if the symmetry/asymmetry deck was stacked deliberately; so also were all the other most basic features of our cosmos. Of course, for all we really know, the universe was created from the outset with a great preponderance of matter over antimatter as an initial condition; but this primordial asymmetry would also be a stacked deck. For us to exist, our universe must contain just the right amount of free matter. 


\section{ii. A Weaker or Stronger Force of Gravity}

If the force of gravity were slightly weaker, the universe would have expanded too rapidly for galaxies, stars, and planets to form. Gravity would have been too weak to pull local clouds of gaseous mass/energy together into heterogeneous clumps. With weaker gravity, the universe would have undergone a rapid heat death. Mass/energy would have dissipated too fast for life to form. The evolution of valuable life is impossible without just the right tug from gravity to form planets with suitable physical and chemical conditions for life's emergence and development. To be life-supporting, hospitable planets also must have stars (suns) produced by gravity over billions of years of time that furnish them with just enough sustained energy, not too little, not too much.

If the force of gravity had been slightly greater, suns would suck in their planets or fail to release enough energy to sustain life. On planets with slightly increased gravity, living things would have to be extremely small and light in weight to avoid breaking apart when they fall. If gravity had been somewhat more powerful, no suns and planets at all would have formed; all regions of the universe in which they actually formed would have undergone rapid gravitational collapse. More powerful gravity would yield a universe full of black holes but no galaxies, stars, and planets. If a universe with greater gravity were to begin with a Big Bang, it would end shortly in total gravitational collapse.

\section{iii. More or Less Mass/Energy}

If the force of gravity were unchanged, but the initial quantity or density of mass/energy or physical particles in the universe were slightly greater or less, the results would resemble those from variations in the force of gravity. With either too much mass/energy or too much gravity, a universe would not expand rapidly enough. It would be too hot for life, and its total duration would be too short for life to evolve. With too little mass/energy or gravity, the universe would expand too rapidly and quickly become too cold for life. Stephen Hawking points out that "If the rate of expansion one second after the Big Bang had been smaller by even one part in a hundred thousand million million it would have recollapsed before it reached its present size."

\section{iv. The Size and Age of the Universe}

Both the size and the age of the universe are closely related to its mass/energy; and as B. J. Carr and M. J. Rees put it, "The Universe must be as big and diffuse as it is to last long enough to give rise to life." A closed universe no bigger than our Milky Way would pass through its entire expansion/contraction cycle in about a year of our time; and valuable life could not evolve. In a small universe of short duration, nucleosynthesis could not produce heavy elements 
like carbon, oxygen, and nitrogen, so essential to life as we know it. Even noncarbonaceous life forms, if there are any, would require some heavy elements, though we do not know exactly which ones or in what proportions.

No enduring life forms could exist within universes consisting solely of volatile hydrogen and/or helium gasses-not even in infinite quantities and configurations. Life requires a diversity of cohesive chemical elements; it cannot be composed solely of hydrogen and helium. No heavy elements were produced in the Big Bang. They require billions of years of cooking time in stellar furnaces. The earliest stars contained no chemical elements heavier than hydrogen, helium, and traces of deuterium and lithium. No life evolved until after the first generation of stars synthesized heavy elements and then exploded as supernovas to scatter their contents through spacetime. Afterwards, gravity slowly reassembled this heavy stardust into later generations of stars with planets. At our stage of cosmic development, this has happened many times; but if it never happened, no life would exist. Anthropic Cosmologists firmly believe that life could not have evolved much faster anywhere than it actually did on earth. Barrow and Tipler recognize that their arguments "use evolutionary timescales as a crucial step." This assumption seems fair enough.

\section{v. Variations in the Electromagnetic Force}

If the electromagnetic force that binds electrons to atomic nuclei were much weaker, no atoms would form, not even hydrogen, much less the heavier elements. If it were only slightly weaker, all stars would be inhospitable blue giants. If it were slightly stronger, no long-lasting hydrogen-burning stars would exist. All stars would be red dwarfs that could not explode as supernovas to distribute heavy elements throughout the universe. Whether slightly weaker or stronger, no long-lasting main sequence stars like our sun would exist to provide the duration and stability of life-supporting conditions essential for the evolution of life.

\section{vi. Alterations of the Strong Force in Atomic Nuclei}

If the strong force that binds protons and neutrons in atomic nuclei were slightly greater, there would be no atomic nuclei, no protons, and thus no atoms at all. If atoms were to form, all hydrogen would burn quickly into helium. The physics is complex, but if the relative strengths of the electromagnetic and strong nuclear forces had been ever so slightly different, either three helium atoms would not have fused to form carbon, or carbon would have been so unstable that it would have fused quickly with a fourth helium atom to form oxygen. ${ }^{6}$ Either way, the cosmos would contain no stable carbon. The very existence of carbon in the universe for the construction of carbon-based life is a striking cosmic coincidence. If the strong force had been slightly weaker than it is, the 
universe would be composed entirely of hydrogen gas, with no heavy elements and no living things. No deuterium, heavy hydrogen composed of one proton and one neutron in its nucleus, would have formed because the nucleus of deuterium is too easily torn apart. No hot stars would exist in an all-hydrogen universe, for even if proto-stars had formed, nuclear fusion could never commence without deuterium to ignite it.

\section{vii. Variations in the Weak Force Controlling Nuclear Decay}

The weakness of the weakforce that controls nuclear decay must be very precise to produce biochemical life. A precisely calibrated weak force is essential for fusing protons into elements heavier than hydrogen. If the weak force were slightly weaker, all the hydrogen in the universe would fuse quickly into helium; and there would be no slow-hydrogen-burning main-line stars like our sun. Heavier elements like carbon, oxygen, nitrogen, and the chemical compounds upon which life depends would not exist. No supernovas could explode to distribute heavy elements through the cosmos if the weak force were any stronger. If the weak force had been only slightly stronger than it is, everything would have turned immediately into iron. What a dead universe that would be!

\section{viii. Different Spatial Dimensions}

Innumerable features of our world are exceedingly fine-tuned for the production of intrinsically valuable lives. With only two instead of three spatial dimensions, no life could exist. Without three spatial dimensions, there would be no sub-atomic particles, no atoms, no molecules, and no organic chemistry to form biochemical life. Edwin A. Abbott's two dimensional "Flatlanders" exist only in fiction, not in fact. Stephen Hawking explains how awkward, indeed how impossible, two-dimensional life would be. Two dimensional animals "would have to climb over each other to get past each other," and a digestive tract passing all the way through them would cut them in half! ${ }^{8}$ More than three spatial dimensions would also be incompatible with life; so, Hawking concludes, "Life, at least as we know it, can exist only in regions of space-time in which one time and three space dimensions are not curled up small."

\section{ix. Additional Fine-Tuned Features}

Contemporary astrophysicists have uncovered a vast array of additional finetuned physical features of the universe like large number coincidences and exacting initial conditions that are necessary for the appearance and development of all life, especially complex valuable life. Very detailed and thorough discussion of the incredibly fine-tuned cosmic coincidences presupposed by the existence of life were published in 1989 by John Leslie, who interprets the data 
Platonically, ${ }^{10}$ and in 1993 by M. A. Corey, who interprets the data theistically. ${ }^{11}$ For more details, read their books!

We have seen enough at this point to understand why Anthropic Cosmologists accept the Anthropic Principle, which affirms that the production of valuable lives is the purpose of our universe. For very good reasons, Atheistic Anthropic Cosmologists accept the Anthropic Principle, the first premise of our Biopic Teleological Argument for the existence of God. Our universe is indeed exceptionally fine-tuned for the production of an immense variety of intrinsically valuable complex forms of life. But they reject the second premise, that God did it; so we must scrutinize their reasons for doing so.

\section{B. Inadequate Non-Theistic Explanations}

No matter how impressive the cosmic coincidences are that sustain our existence, the Biopic Teleological Argument for the existence of God does not succeed if it can be shown that our universe's fine-tuning for life results from something other than a divine transcendent benevolent Supercosmic Intellect; but this cannot be done.

In earlier chapters, we saw that most Anthropic Cosmologists reject the theistic solution and try to account for the life-sustaining order of our world with the hypotheses that it was caused by: i. Infinitely Many Universes, or ii. the Principle of Plenitude, or iii. Nothingness. All these non-theistic solutions presuppose that our favorably ordered world was produced by blind chance. Earlier chapters demonstrated that none of these alternatives can be defended. This does not show with absolute certainty that God is the best explanation because other unanticipated explanations might arise (always a problem with disjunctive arguments); but these will just have to be confronted if and when they appear. Without repeating every detail, consider these reminders of why atheistic explanations of cosmic teleology fail.

\section{i. Infinitely Many Worlds}

Most Atheistic Anthropic Cosmologists think that a divine Supercosmic Intellect can be avoided by appealing to the unverified and unverifiable existence of infinitely many worlds. They claim that there are or have been an infinite number of transcendent antecedent and/or contemporary universes, that this infinity of universes in Supertime or Superspace actualizes all possible individuals, universal properties, and relations, and that it occasionally includes a life-supporting universe like ours purely by accident. If these metaphysical assumptions are indefensible, infinite worlds metaphysics fails to provide a plausible alternative to a Divine Supercosmic Intellect. Earlier, we determined that these assumptions do fail-for the following reasons. 
No good scientific or empirical reasons or evidences show that infinitely many worlds exist, even if prominent scientists say so. No infinitely transcendent Supertime or Superspace containing an infinite number of particular spacetime systems or universes can be verified directly or inferred inductively or indirectly from available evidence. The creation of our world by an infinity of antecedent worlds, by infinite Mother Spacetime, or by infinite world divisions is not an empirically confirmed belief. "Scientifically" postulating infinitely many universes flagrantly, infinitely, violates Ockham's razor. No antecedent oscillating universes can end in singularities because, by definition, time, space, and physical causation are non-existent in singularities. Singularities provide no spatiotemporal or causal corridors for linking universes. Yet, without singularities, increasing entropy would carry through an infinity of antecedent oscillating universes and make our world infinitely chaotic-anything but life-supporting. But here we are!

Roger Penrose maintains that although singularities are infinitely small, dense, and curved, they can nevertheless be structured with low entropy. The initial singularity that originated our universe was structured with low entropy or disorder, and it has been losing it ever since. Recall that since singularities are not empirical entities, any claims about them can be translated without loss of empirical content into the language of creation ex nihilo. Thus, Penrose's claim about the low-entropy singularity that initiated our universe is empirically indistinguishable from the theistic claim that the original stuff that God created from nothing (or from a "singularity") at the beginning was divinely ordered with low entropy.

That God created the low-entropy grandly-unified mass of energy that began our universe is much more plausible than that it was caused by an antecedent universe's Big Crunch. Most cosmologists today agree that an antecedent universe's final singularity, culminating its Big Crunch, would contain extremely high entropy or disorder. ${ }^{12}$ Even if the initial singularity of our universe were really nothing, as in "created out of nothing," our cosmic epoch was ordered from the outset with low entropy. No high entropy Big Crunches could ever produce the low entropy Big Rebounds required by Oscillation Cosmology because great chaos is never the direct and immediate cause of great orderanother well confirmed empirical truth. More technically, no state of affairs being torn apart by rippling Weyl curvature is ever followed immediately by its total elimination.

Atheistic Anthropic Cosmology's other worlds are just as transcendent, non-empirical, and Other Worldly as Heaven and Hell in traditional Christian theology. Atheists may believe in them by a heroic leap of faith, but no rationally defensible evidence supports their existence. Naturalists should reject all cosmological other-world-ensembles for the same reasons that they repudiate religiously based Other Worlds. Yet, Naturalism can be defended only by 
appeal to Other Worlds! We know, because of the Big Bang, that our world has not always existed.

Even if infinitely many worlds were actual, they would not explain the existence of our life-supporting world. An infinity of universes in time or space will not actualize all possible individuals, universal properties, and relations. Infinity cannot be "used up," not even by infinity. Infinity minus infinity equals infinity. Numerical spatiotemporal infinity alone does not guarantee that a lifesupporting universe will come along after a sufficient number of lifeless ones have been used up. Lifeless universes could easily be repeated inexhaustibly in time and/or space, either by causal necessity, or by accidental quantum fluctuations. Atheistic explanations commit the inverse gambler's fallacy.

David Hume maintained that all possible configurations of matter would be actualized in an infinite amount of time, but the very idea is incoherent, for many configurations are incompatible with others. It is logically possible that a monkey typing the letter "a" would type only that one letter from infinity to infinity, to the exclusion of all other possible worlds. Nothing in the concept of infinity requires any diversification at all. A monkey banging on a typewriter could just hit one key forever-in Eternal Recurrence. The assumption that our life-supporting universe is made more probable by the prior existence of an infinite number of lifeless worlds commits the inverse gambler's fallacy.

A numerical spatiotemporal infinity should not be confused with infinite individual, qualitative, and relational diversity. Bare infinity lacks a mechanism for insuring any diversity, much less the right kind of physical diversity for life. Unless some Divine Agent of Limitation and Selection chooses diversity, neither spatial nor temporal infinity as such is compelled to manifest any diversity at all among actual universes, much less infinite diversity. Some diversity among bubble universes, if any others exist, may happen accidentally through quantum fluctuations; but an infinite number of accidental universes cannot use up an inexhaustible class of lifeless universes to guarantee the actual appearance of a life-supporting one like ours. Given an infinite number of shoes, it is possible that no shoe fits! Trash universes could easily be repeated endlessly, even if caused by quantum fluctuations. Without God, they probably would be. Mere infinity gives no assurance of any diversity at all; inane sameness can be reiterated forever. Either the Principle of Plenitude or God might account for diversification among universes, but God alone really explains it because plenitude will not work. Why not?

\section{ii. The Principle of Plenitude}

The Principle of Plenitude affirms that all possible worlds are actual. It is a theological principle, not an empirical or scientific fact. It is empirically unverified and unverifiable; and it violates the principle of parsimony, Ockham's razor, in every conceivable way. 
The Principle of Plenitude is derived from Platonic Theism, where it defines the Greek ideal of divine perfection. There are other arguments for its truth, but none that can really be defended philosophically. ${ }^{13}$ Theists need not accept it unless they agree that Divine perfection necessitates the actualization of every possibility-including horrible as well as beneficent possible worlds; but actualizing all possibilities is not possible; the very idea is incoherent; and infinity cannot be exhausted. World-ensemble metaphysics is not natural science. Blind faith may postulate infinitely many diversified worlds; but that is all it is-blind faith. With or without singularities, no evidence available to us indicates that infinitely many worlds exist, diversified or not. Consider the following argument.

If infinitely many diversified worlds exist, a life-supporting world like ours will come along occasionally purely by accident.

Therefore, our life-supporting world came along purely by accident.

Deductively, this conclusion does not follow. From "If $p$, then $q$ " alone, we cannot conclude " $q$ ". Only if we also know " $p$ "-that infinitely many diversified worlds exist-can we conclude " $q$ "-that a life-supporting world like ours will come along occasionally purely by accident. We do not know that " $p$ " is true, and we have many good reasons for thinking that it is false. The existence of an infinity of diversified worlds-plenitude of creation-may be advanced as an explanatory hypothesis, but it does not explain a life-supporting world, and it cannot be successfully defended.

Admitting that other worlds are logically possible concedes absolutely nothing about their actuality. For every contingent "possibly so," there is a "possibly not." Possibly, many other worlds exist; possibly, no other worlds exist. These possibilities are mutually exclusive. Possibly, you are extremely wealthy; but that puts no money into your bank account. We should not confuse abstruse possibility with high probability, credibility, actuality, or reality. Atheistic Anthropic Cosmologists regularly make such confusions.

Plenitude, the actualization of all possible worlds, is logically incoherent. The non-existence of every possible world is also a possible world. Mutually exclusive whole universes and sets of universes are logically possible, and so are mutually exclusive alternatives or variations within any one universe. Our own world (or all worlds) could have been either life-supporting or non-lifesupporting, quantum or non-quantum, oscillating or non-oscillating, Divinely created or not so.

Plenitude's requirement that all possibilities be actualized in an infinite number of universes is not logically coherent. As Leibniz knew, there are logically incompatible, mutually exclusive, or "incompossible" possibilities. It is logically possible that an infinite number of worlds are all life-supporting, and that none of them are; but these possibilities are incompossible, that is, they are 
possible separately but not possible together. Possibly, nothing exists; possibly, something exists; but these possibilities cannot both be realized. Possibly, every strand of past oscillating universes ended in nothingness, in which case there would be nothing now; possibly they all ended in openness, in which case they could not explain our Big Bang. The realization of all possibilities implies that nothing now exists, which is obviously false! It also implies that everything now exists, which is equally false! Possibly, a single lifeless universe recurs eternally in every tiny detail; but this would rule out all possible life-supporting universes, including our own. The very idea of realizing all possibilities makes no sense. We cannot infer from an incoherent concept that our kind of universe is bound to occur accidentally from time to time. It is logically impossible, logically false, that everything possible is actual. Incompossibles are possible separately but not together. Choices between possible worlds have to be made; actual existence is competitive and selective. Who chose our life-supporting cosmos? Not plenitude!

Plenitude is an abstract, disembodied, normative principle. At best it can only be a formal cause. Nothing totally abstract, disembodied, and normative can make actual choices or be the efficient cause of anything. Abstract, disembodied, normative principles bring about results only when contained within and intentionally acted upon by concretely existing individuals who understand them. God is required for the causal efficacy of plenitude, or more selective creation. A good God would not act upon it, would not create every possible evil or trivial world.

Atheistic appeals to plenitude to avoid God are self defeating. If all possibilities are actual, then a God who selects among possible worlds exists since such a God is possible! Indeed, all conceivable gods exist, assuming that the idea of such is coherent. And no God exists, since that too is possible.

\section{iii. Nothingness}

Nothing is ever caused by pure nothingness. Out of nothing, nothing comes. All experience and theory grounded in experience, including quantum physics, is against the Big Accident hypothesis that nothing causes something. Quantum physics does not abandon causality altogether; it always retains necessary causal conditions and relinquishes only sufficient causal conditions. Abstract disembodied physical principles like quantum laws cannot exist and act within nothingness, for then nothing would be something after all. No good empirical scientific evidence shows that infinitely transcendent Superspacetime exists beyond or before our spacetime, or that it has a quantum bubbly structure that produces spontaneous fluctuations. Theology may require Superspacetime, but not science. Non-quantum worlds devoid of quantum perturbations are logically possible in infinite numbers. Pure nothingness cannot guarantee anything, especially that endless universes are governed by quantum laws, or that an 
occasional quantum universe is accidentally life-supporting. Since non-quantum worlds are possible, universes capable of quantum fluctuations require their own explanation and do not ultimately explain anything. What selects for quantum instead of for non-quantum worlds? Nothingness selects nothing.

\section{B. Probabilities Favor Divinity}

The best explanation for our universe's fine-tuning for life is that an existing God, a wise and benevolent being of supercosmic proportions, chose and created it knowingly and intentionally. Various strategies tend to show that this conclusion is true. Up to this point my strategy has been to demonstrate that alternative explanations of the cause of the Big Bang are indefensible. Nontheistic explanations really do not work. Often, the winner of a contest is the last one left standing on the field.

Yet, it would be nice to have more positive or constructive evidence for thinking that God chose the life-supporting features of our world. Probabilities positively favor Divinity, but this needs some explaining.

In one sense, we cannot determine the probability of the occurrence of a life-supporting universe. Probabilities are normally assessed statistically by comparing an actual instance with other actual members of a known class; but no existential probabilities are available for unique entities that belong to classes having only one member. Charles Sanders Peirce remarked that universes are not as plentiful as blackberries. As far as we really know, our 15 billion-yearold universe is unique, the only one of its kind. We have access to no other actual universes with which we can compare it.

Recognizing that we experience only one world, David Hume argued that we are entitled to proclaim the truth of our theory of the origin of the universe only if innumerable universes have been formed before our eyes. Obviously, this has not happened. Neither theists nor atheists have ever seen worlds formed before their eyes, so they are both in the same boat in this respect. Atheistic world-ensemble metaphysicians seem to be unacquainted with David Hume, or they read him very selectively! Hume's own supposition of innumerable worlds existing in infinite time is inconsistent with his own skepticism!

In another sense, however, probabilities about ordered universes can be determined. A unique actual entity can be placed within a class of possible entities, and its absolute probability can be calculated. To determine the probability of a life-supporting world order, our actual ordered-for-life universe can be compared with all possible members of the class of universes that might exist. Appeal to absolute probability is commonplace in quantum mechanics, where determining the probability of a quantum event involves summing over all logical possibilities for that event.

Recall that physicists can assign numbers to every basic physical dimension of the universe-its density, expansion rate, entropy, the force of gravity, the 
strong nuclear force, the weak and electromagnetic forces, the speed of light, Hubble's constant, Planck's constant, and so on. For life-supporting universes, permissible numbers for each such basic component of life-supporting physical reality fall within a very limited range. This leaves an infinite range of numbers for each component that would result in lifeless universes, all of which are possible worlds. For every measurable component of life-supporting universes, the range of right numbers is finite; the range of wrong numbers is infinite. This is also true of the way in which all the relevant numbers must be integrated harmoniously in order to make a life-supporting universe.

Each wrong number correlates with a possible lifeless universe. Within the class of possible designs for universes, life-supporting ones are infinitely improbable. Recall Stephen Hawking's comment that

There are relatively few ranges of values for the numbers that would allow the development of any form of intelligent life. Most sets of values would give rise to universes that, although they might be very beautiful, would contain no one able to wonder at that beauty. ${ }^{14}$

Steven Weinberg conjectures that "The existence of some form of life will turn out not to require any very impressive fine-tuning of the laws of nature,"15 and he doubts that we will find "any sign of the workings of an interested God, in a final theory." ${ }^{16}$ Yet, even if conditions favoring the existence of life are fairly broad and do not require extensive fine-tuning, the range of permissible physical numbers is still very finite, and the range of impermissible numbers is infinite. Our own world order is very impressive because the number of ways to go wrong with any two basic physical components is infinity multiplied by infinity-which is still just infinity, but putting it this way makes the point more impressive! If all possibilities are actual, no life-supporting universe exists now anyway, since it is possible that no life-supporting universes exist at all. An infinity of life-defeating aberrations corresponds to every finite range of cosmic conditions that would support life. Incomprehensible (to us) intelligence and skill are necessary to get single as well as conjoint conditions right for a lifesupporting cosmos.

The order of our universe most resembles the intricate order of the most complex products of purposive human intelligence, not the order of chaos or chance. Anthropic Cosmologists are well aware of this. Roger Penrose, for example, points out that a life-supporting universe must begin in a state of extremely low entropy or disorder, and that the possibilities and probabilities for high entropy universes are immensely greater than for low entropy universes. To understand how enormous the odds are against getting a low entropy universe, Penrose suggests, we should picture the Creator poised before a system of space as voluminous as our physical universe, each point of which represents a distinctive universe. The Creator's task is to stick a pin into this vast system 
of space at exactly the one right point that will produce an initially low entropy life-supporting world. The rest of the volume corresponds to lifeless high entropy universes, so they would be exceptionally easy to hit; but the chances of hitting the tiny volume that represents a life-supporting low entropy universe are exceedingly minute. ${ }^{17}$ The Creator's aim must be precise to an accuracy of "one part in $10^{10^{123} \text { " }}$ if the intended target is a low entropy life-supporting universe. This number is so enormous, says Penrose, that we could not write it down in ordinary mathematical notation even if we wrote a " 0 " on every particle of matter in the universe! 18 $^{8}$

Penrose actually underestimates the odds because his huge number is still finite; and the odds against life are really infinite. The number of non-life points on the Creator's target is infinite; life-points are finite indeed! Arranging a universe for life is no task for mere chance. The probability is overwhelming, indeed infinite, that a numerical infinity of universes in space and/or time would be wrong for life. Only a Divine Supercosmic Intellect could successfully select for and create a low entropy universe.

In 1980, Fred Hoyle, traditionally no friend of Theism, was overwhelmed by the realization that the chances are astronomically small that any universe would accidentally produce two things essential for life, enzymes and carbon. Hoyle says he was "plagued by the thought that the number of ways in which even a single enzyme could be wrongly constructed was greater than the number of all the atoms in the universe," and he found the conclusion irresistible that enzymes are produced

by thought, not by random processes. Rather than accept the fantastically small probability of life having arisen through the blind forces of nature, it seemed better to suppose that the origin of life was a deliberate intellectual act. By "better" I mean less likely to be wrong."

In 1953, Hoyle was the first to discover how nearly impossible it is to get stable carbon and oxygen from stellar nucleosynthesis. In 1980, he reflected on the odds against getting carbon, with properties so essential to life as we know it, by pure chance. He concluded that "Some supercalculating intellect must have designed the properties of the carbon atom," and that "The carbon atom is a fix." ${ }^{20}$ Considering the chances of getting roughly equal quantities of carbon and nitrogen by stellar nucleosynthesis, we must again conclude that this is "another put-up, artificial job." Hoyle continued,

A common sense interpretation of the facts suggest that a superintellect has monkeyed with the physics, as well as with chemistry and biology, and that there are no blind forces worth speaking about in nature. The numbers one calculates from the facts seem to me so overwhelming as to put this conclusion almost beyond question. ${ }^{21}$ 
Theism is more probable than Atheism because it provides the most reasonable and thus the best justified explanation for the existence of our kind of universe. Saying that one philosophical position is "more probable" than another is just a shorthand way of saying that the philosophical case for the one is stronger than for the other. In that sense the Teleological Argument in modern biopic dress affirms that the existence of God is more probable than God's nonexistence.

The Teleological Argument tells us something important that the Cosmological Argument does not disclose, namely, that the ultimate cause of the universe is intelligent and well-intentioned or benevolent. The beneficial order of the world, especially its capacity for producing an immense variety of intrinsically valuable forms of life, including human life, reflects the stupendous knowledge, skill, and generosity of a benevolent, transcendent, personal, causal agent-God.

The central question raised by the Biopic Teleological Argument is simple. Did the ultimate cause of the universe know and care about what it was doing, or not? Did our life-supporting universe originate by intelligent choice or by blind chance? Naturalistic, atheistic, infinite worlds metaphysics says, "By dumb chance." Theism says, "By brilliant choice."

\section{Conclusion: God Ordered Our World}

Our Biopic Teleological Argument concludes that an existing God, a benevolent Supercosmic Intellect, intentionally and knowingly selected and brought about the life-supporting order of our universe; but this conclusion does not follow simply from the authority of preeminent cosmologists like Penrose and Hoyle. The evidence to which they call attention is crucial, and it strongly supports all the premises of our Biopic Teleological Argument. Thus, most likely, a universe ordered for the production of an immense variety of complex and intrinsically valuable forms of life was caused or created intentionally by a transcendent benevolent Supercosmic Intellect.

Alternative accounts fail to explain the stupendous cosmic coincidences that conspire to produce life in our world. The only reasonable hypothesis is that an Ultimate Cause, namely God, who knew and cared about what it was doing, is responsible.

Eliminating the competition is a perfectly respectable way to argue in philosophy. Often, the best available proof is a disproof of the alternatives; the solution that best withstands the process of critical examination is the winner. At this point in the battle, only one plausible explanation remains: God did it. God knowingly and intentionally designed our universe for life.

Many objections may be raised to the teleological argument. Atheists do not give up without a good fight, so let us turn now to some commonplace misgivings. 


\section{Critique and Defense of the Biopic Teleological Argument}

The Teleological Argument, though very popular with religious believers, has been under assault almost from its inception in ancient Greece. Most professional philosophers today mistakenly assume that critiques by Hume and Kant made it utterly indefensible. The most serious contemporary objection to the Teleological Argument is that an infinite worlds metaphysics makes God unnecessary; but we have already disposed of that alternative, along with the difficulty that probabilities cannot be calculated for life-supporting universes. Other objections remain, and to these we must now turn.

\section{A. Natural Creation of Order}

If the universe naturally creates order, no external Divine Designer is required, some critics insist. Victor J.Stenger maintains that the life-supporting order of the universe occurred by chance, Not by Design, as the title of one of his books indicates. ${ }^{22}$ In both Not by Design and The Unconscious Quantum, Stenger stresses matter's capacity to organize itself into meaningful patterns and contends that this obviates the need to resort to a divine designer to explain the order of the universe and the origin of life and mind. Eric Lerner also claims that, not divine guidance, but a "natural tendency of all matter, both animate and inanimate, to evolve toward higher rates of energy flow, toward the capture of greater currents of energy," adequately explains humanity's origin and development. ${ }^{23}$ Both Stenger and Lerner take the creatively self-organizing capacity of the physical world as a given that needs no explanation; but it does. Why is our physical world capable of self-organization when infinitely many alternative worlds would have no such capacity? Explaining that is imperative!

According to Stenger's Not by Design, the natural order of things permits chance occurrences; and chance occurrences eventually add up to an ordered world in an infinite amount of time. However, an infinite amount of time is not available if the Big Bang is right; and even if time were infinite, we could not know it scientifically. Also, random or chance events presuppose order and can be recognized as such only against a background of order. Given all the laws of physics, a deck of cards can be randomly shuffled; but with no laws of physics at all, there can be no random shuffle. Randomness presupposes orderliness

Stenger has the effect before the cause, the cart before the horse. The basic natural order of things permits chance occurrences that further increase order; but without a very special basic initial order, no increase would occur. Certain types of minimal order produce more order, but absolute chance or chaos produces nothing. That a very minimally ordered universe would not be creatively self-organizing is infinitely probable.

Even if absolute chance could produce well ordered universes, which it doesn't, the probability is overwhelming that they would be lifeless. Why do we 
live in a quantum universe where chance is real instead of an old-fashioned Newtonian universe devoid of unpredictable spontaneity? Why do we live in a universe in which law and chance together contrive to produce intrinsically valuable forms of life instead of desolation? Given a minimal degree of order, why does chance (or creativity) produce more order, life-supporting order in particular, when it could produce infinite chaos or an infinite number of complexly ordered hostile-to-life environments? These questions require answers. Skeptics and naturalists like Stenger and Lerner have no good answers.

According to Lerner, there exists a "natural tendency" toward order. Yet, this natural tendency depends upon a deep structure of order in nature, which is exactly what the Biopic Teleological Argument is all about. Why is the basic order of the universe so constructed that it produces more order rather than less? In particular, why does it regularly produce beings who capture higher and higher energy flows, as Lerner puts it, when there are infinitely many other ways to order, or to disorder, a universe, some of them very complex? Why does our universe exhibit what Holmes Rolston, III calls an "upslope" to the long-range curve of evolutionary development, when neither survival nor adaptation to environment require it? $?^{24}$ Why does the most basic physical order of the universe permit life to occur at all when there are infinitely many ways to fail?

Natural tendencies are existing patterns of order, but any primal creative order that produces more order requires its own explanation; it cannot just be taken for granted. Why does our universe have a life-supporting order when life-defeating orders are overwhelmingly more probable? The best explanation, according to the Biopic Teleological Argument, is that our world was designed by Divine premeditation to have a deep level of life-promoting, partly selfcreative, partly self-organizing order. Atheists do not and cannot explain adequately why fundamental self-organizing propensities exist within our universe. They just take them for granted.

\section{B. The Insignificance of Life in a Vast Universe}

In a preceding chapter, we confronted the unsubstantiated view that life as we know it is insignificant because it is so small and short in relation to the vastness of spacetime. This fallacy-smallness equals insignificance-frequently resurfaces as an explicit objection to the Teleological Argument. The problem is, how can God's purpose for the universe be the creation of intrinsically valuable life when complex life exists only on earth, and merely for a few hundred thousand or million years at most? Intelligent life-forms belonging to the species Homo sapiens have existed for less than five hundred thousand years or so in a fifteen to twenty billion year old cosmos. Putting time scales for cosmic and biological evolution into perspective, Philip Hefner wrote, 
If we were to plot this sequence of events on a calendar with one day equaling 14 million years and one hour equaling a half million years, our natural history would look like this: on January 1 the earth's crust congealed; dinosaurs appeared on December 21; Neanderthal man arrives only at 11:50 p.m. on New Year's Eve. Relative to the overall history of the natural cosmos, the role of the human species is staggering in its minuteness. ${ }^{25}$

By now we know that and why the intrinsic value of our lives does not depend on vastness of size or duration, or on our utility in contributing toward some Enduring Grand Objective. God does not treasure us for these reasons, and we should not disvalue ourselves and one another for such spurious deficiencies. Our lives as they are exist for themselves, for other creatures, and for God. The value of life is located in the process of living and enriching it. All living things are beloved by God, and God's interests in creation are biopic, not merely anthropic, if Process Theologians are right.

Though presently unverified, that living creatures exist on numerous planets in innumerable galaxies scattered throughout the cosmos is highly likely. ${ }^{26}$ Life in some of these places is probably far older and much more advanced than on earth. As Robert Jastrow speculated in 1980,

If life is common in the cosmos, which is possible, then most of that life has advanced billions of years beyond us in evolution. And what does a billion years mean in evolution? A hundred years means nothing; that is only a few generations. A thousand years is not much more. A million years is the time it takes a new species to develop. What does a billion years mean? A billion years ago the fossil records show that the highest form of life on earth was the worm. So, if there are intelligent entities in space, out there, they are as far beyond us as we are beyond the worm. They may know the answer to the cosmic mysteries. They may know the meaning of the big bang. ${ }^{27}$

In 1997, Jastrow warned that if we ever make contact with extraterrestrial civilizations far older and more advanced scientifically than our own, our civilization might be destroyed. This seems to be the fate of all "primitive" societies that come into contact with technically advanced cultures separated by only a few thousand years of cultural evolution. Jastrow observes that "On this planet, contact between scientifically advanced civilizations and a primitive society...typically results in the destruction of the less-developed culture"; and he asks, "What may be expected of a meeting between civilizations separated by a billion years? Will we survive the encounter? I see no grounds for optimism." ${ }^{28}$ 
Perhaps we should hope that long-distance space-travel is not possible, that Star Trek and its sequels are only pipedreams (which they are), that the basic physics of the universe forbids long distance space travel even for scientifically advanced societies. Perhaps we should be thankful that stars with inhabitable planets are separated by such vast distances, and that no living beings can get from there to here. Perhaps God in his wisdom made it so!

Or perhaps we should hope that, unlike here on earth, ethical development has matched pace with technological progress in advanced civilizations beyond our corner of the Milky Way. Usually, the most ethical thing to do in relation to lesser forms of life is just to leave them alone. Far, far away, some alien civilization with a "prime directive" of noninterference may be doing just that for us. Maybe so; maybe not.

At any rate, cosmic life is probably of much greater duration and extent than earth life. If so, God knew, loved, and interacted with intrinsically valuable living things for billions of years before he had the dinosaurs or us to love. Extraterrestrial conscious beings would also be ends in themselves. So were and are members of more "primitive" human cultures and humanoid species. So were the dinosaurs. So were and are all sentient living things, including ourselves. If and when our species is sufficiently advanced, our ethical ideals and practices will reflect this ecological theology.

Life is scarce in our universe in the sense that vast regions of spacetime are unoccupied by any forms of life. No other planets in our solar system support life as far as we can tell, though Mars may have done so in the distant past. In 1996, two meteorites from Mars discovered in Antarctica were determined to contain organic compounds, best explained, some said, by bacteria-size organisms that lived on the red planet billions of years ago. In December 1996, NASA scientists announced that a large lake of frozen water has been located on the dark side of our moon. Since then, water has been found on Jupiter's moon, Europa, and in vast regions of "empty" space. Do traces of primitive aquatic life exist in some of these places? Continued space exploration may soon give us the answer.

All stars are directly inhospitable to life and many have no planets at all, much less inhabitable planets. In 1994, astronomers discovered the first solid evidence-orbital deviations of stars-for the existence of a planet in another solar system, and many others have since been identified. ${ }^{29}$ Skeptics originally suggested that in some instances astronomers were seeing only earthquake-like vibrations on the surface of these stars, not wobbles caused by orbiting planets, but defenders justifiably did not concede defeat. In 1999, a large extra-solar planet was actually photographed as it crossed its star. Sky and Telescope exclaimed, "For the first time a planet of another star has been seen crossing the star's face, allowing astronomers to measure directly the planet's size, mass, and density. ${ }^{30}$ Despite their relative scarcity, billions of sun/planet systems probably exist, and many of these may teem with life. If, on average, only one life-sup- 
porting planet is located in every galaxy in the universe, at least one hundred twenty-five billion life-supporting planets would exist!

If most of the universe is uninhabited, this does not mean that it is a wasteland. God could, and probably does, take keen aesthetic interest and delight in non-living nature, just as we do. Astronomers have discovered that the universe is much more active and violent than once thought. Perhaps God enjoys celestial fireworks as well as sunsets, grand canyons, frozen wastelands, and scorched deserts. Just because God created the universe primarily for life, it does not follow that God can have no other interests. Since God's time is limitless, God never has to rush anything. God has plenty of time for everything, including appreciating the sublime beauty of vast expanses of lifeless nature. We find great beauty and sublimity in the non-living parts of nature, including the starry heavens above, so why can't God? God's reality includes all reality, both living and non-living; but the starry heavens above would be no less magnificent if they were starry heavens within, as they are for God.

\section{The Big Mess: Evil and The Religious Ambiguity of Order in Nature}

Must every detail of ordered reality result from a Divine plan or design if God is as intelligent, powerful, and morally good or benevolent as the monotheistic religions profess? David Hume suggested that our evil-infested universe could have been ordered only by a stupid, weak, or demonic divinity. Perhaps it was designed and created by a Malicious Demon who formed it for the purpose of torturing its inhabitants. From the observable order of nature, can we really tell that its transcendent Divine cause is intelligent enough to know what it is doing, and that God's enduring character and intentions are morally good or benevolent? Skeptics have serious and legitimate doubts. The world is such a big mess that it really might not have been designed by an intelligent, powerful, and benevolent God. Can we conceive of a better way to introduce and organize the initial conditions of and conditions within the universe for producing life and for avoiding evil?

The reality of evil is particularly perilous to the Teleological Argument. The God of Classical Theism foreknows, causes, and plans every minuscule detail of creation. Both the general design of and every particular feature of the universe expresses God's Grand Plan. This is implausible for many reasons in addition to the problem of evil. Defenders of absolute grand design have actually claimed that God deliberately created fleas and bedbugs to be black so that people could detect them more easily on white sheets, that God intentionally created dogs multicolored so that we can distinguish them more easily from the furniture, ${ }^{31}$ that God purposefully created more human males than females so that surplus males can be expended in war, and that absolutely every horrible thing that happens expresses God's will and God's deep but mysterious plans and purposes for creation. In the final analysis, God created the best of all 
possible worlds. Leibniz said so explicitly, but Voltaire vanquished the idea in his Candide.

Why wouldn't an omnipotent, omniscient, and omnibenevolent deity create only the best of all possible worlds-one in which every particular evil contributes necessarily, directly, and decisively to some great good? Why would God ever settle for a merely good world-one in which, on the whole good prevails, or at least has an opportunity to prevail, over evil?

The "best of all possible worlds," traditionally understood, was a universe for which God foreknew, preordained, and selected every detail of existence to achieve an absolute concord in which every distinct evil, whether apparent or real, contributes in perfect measure to the achievement of some greater good, some ultimate harmony of all things. In this best of all possible worlds, a flawless, eternal, and changeless divine plan is played out in every spatiotemporal event; and God is the ultimate decision-maker who decides and determines everything, including what we will decide. In it, absolutely everything that happens directly expresses "the will of God" and God's Grand Plan for all of creation. This feature of Classical Theology often infects popular religion.

The trouble with the best of all possible worlds, thus conceived, is that it is not the best of all possible worlds! It contains no creaturely initiative, freedom, creativity, or originative decision-making. God makes all the decisions and is responsible for absolutely everything. However, an even better world is conceivable-one in which every complex individual knowingly, freely, creatively, and responsibly chooses what is good or best and acts rightly. But this is precisely the kind of world that God alone could not create because, in this really best of all possible worlds, God is not the sole originative decision maker. In it, creativity is distributed to many if not to all creatures; and they are cocreators with God. God always has to settle for a merely good, not an absolutely perfect, world because in the truly best of all possible worlds, God is not and could not be absolutely in control of everything. Absolutely controlling free creatures is logically impossible and morally repugnant.

Creating a universe containing co-creative creatures is always risky business, for free creatures must, by definition, be able to choose without encumbrance both for and against the right and the good. The overwhelming probability is that at times they will choose against, and then there will be no perfect, calculated, and preordained harmony in which every evil achieves some particular good, in addition to the goodness of creativity and freedom themselves.

Process Theism denies that God absolutely controls and plans everything from eternity, especially particular evils. God's eternal Primordial Nature has general aims and objectives-like creating richly populated worlds in which desirable feelings and other goods are actualized in many species of living creatures; but God did and could not plan every detail of existence from eternity because the creatures are partly self-creative, are co-creative with God, and thus have some say-so themselves about what will come to be. 
God did not timelessly calibrate and predestine that any individual person will exist, that he or she will have specific parents, marry a specific soul-mate, have a specific character, suffer particular ills, make very specific right or wrong moral and religious choices, and end up in Heaven or Hell. In his Consequent Nature, God makes and remakes plans to fit contingencies and choices as they arise in the created world. God responds appropriately to decisions made freely by spatiotemporal creatures and wills the best possible outcome for every undesirable spatiotemporal impasse, both within his own experience and within the world itself; but even this Divine will can be thwarted by co-creative decision-making creatures. God deals with unpredictable free choices and contingencies within the universe as they arise, not from eternity. God envisions alternatives for future realization while not knowing in advance which path will be chosen by co-creative creatures. No matter what the creatures decide, God wills to bring the best out of every bad situation, to assimilate evil into his own experience in the best way possible, and to bring as much good as possible into the world out of the evil within it. Even here, God's will can be frustrated and impeded by creaturely freedom.

The existence of evil is an insuperable obstacle to believing, not that a good and powerful God exists, but that God has an absolute, detailed, and eternal Grand Plan for everyone and everything, that God is a doting parent who will not let his children go and grow on their own.

When innocent persons, especially children, suffer pointlessly and die prematurely, as they so often do, could these particular events express the foreknowledge, causation, and inscrutable but still benevolent purposes of God? Classical Theism answers affirmatively, but always with the qualification that we cannot always understand how. When horrible natural catastrophes and moral atrocities occur, popular religion, perverted by Classical Theism, often assigns them to "the will of God." If this is right, however, we should conclude that God is really our enemy, not our friend, that God and the Devil are identical, that God really is a Malicious Demon after all. With an ultimate friend like such a vicious God, who needs a supreme enemy like the Devil?

If God, the transcendent cause of all creation, is timelessly omniscient as Classical Theists believe, he surely knows from eternity that horrors happen; if he is the omnipotent and sole originative or first cause of all that transpires, he surely causes all particular horrors; and if everything that occurs expresses God's purposes, he surely purposes or intends such horrors in every instance. From a world deliberately ordered to produce innumerable unthinkable harms to innocent creatures, how can we infer the existence of a divine Benevolent Superintellect? The task of theodicy is to reconcile the obvious presence of enormous evil in the world with belief in an all-powerful, all-knowing, allbenevolent, and all-compassionate God. Can this be done?

The eternally predetermined best of all possible worlds of Classical Theology is not acceptable. A plausible theodicy requires Process Theology's world 
in which good predominates over evil, or at least has a decent chance to do so, and where freedom and creativity are among the greatest goods of all. A credible theodicy must show that more good than evil exists on the whole within the universe, or at least that the universe is ordered to allow for this possibility. Some attempts to show this are clearly implausible.

\section{i. Solutions that Don't Work}

Classical Theists often argue that all evil is really good in disguise; but this makes us wonder if all apparent good isn't really evil in disguise. If we cannot identify and distinguish between good and evil when we see them, all our value judgments are suspect. If seemingly bad things can be good on the whole, then seemingly good things can be bad on the whole; and we cannot tell which is which. Theodicy tries to show that God is really good, despite all the evil in the world; but this conclusion is completely unwarranted if what we construe as goodness can be evil in disguise, and vice versa. Consider the fate of the rooster who concludes that its human feeder is a benevolent provider; but then the fatal day comes when it loses its head!

Classical Theologians often contend that evil in parts of creation is necessary for the perfection of the whole, but our finitude and ignorance prevent us from seeing how. As the dark areas of a painting contribute to the beauty of the whole painting, or as the bass notes of a musical composition contribute to its overall harmony, so evitgin the wortat intributes to its comprehensive perfection, even if only GodKatows how: Despite appearances, they say, we live in the best of all possible worlds.

Unfortunately, neither dark colors nor bass notes are evil, so the aesthetic analogy is inappropriate from the start. We can understand how they contribute to the goodness of aesthetic wholes, but this cannot be said for many familiar situations containing great evil. The aesthetic analogy supposedly shows that the whole of creation is perfect in every detail, even though we cannot comprehend how. Only our ignorance can make it work. "Inscrutable" is an attribute of God in Classical Theology, including the "Westminster Confession."

Jonathan Edwards argued that sending the great bulk of mankind to eternal perdition is necessary for the perfection of creation as a whole; but, he admitted, we may not see exactly how, especially if we happen to be one of the damned! His God clearly violates Kant's Categorical Imperative and treats damned persons and all victims of tragedy merely as means to the perfection of the whole of creation, not as ends in themselves. The aesthetic analogy fails to tell us whether the transcendent Creator is benevolent or malicious in intent. If the totality is beautiful to God but inscrutable or horrible to us, this does not solve the problem of evil for us! Saying that God knows the answer does not provide us with an answer! We are the ones who need a solution to the problem of theodicy, especially if the Teleological Argument works. 
So how can a powerful transcendent Creator be a Benevolent Superintellect, despite the presence of evil in the world? No single, simple magic bullet neatly solves the problem of theodicy. Its solution, if one is available at all, results from the cumulative weight of many considerations. The success or failure of theodicy is a matter of fallible and variable judgment. Thoughtful persons can honestly disagree about it. Massive evil in the world really is the greatest obstacle of all to belief that a good God designed the universe for benevolent purposes. Without a theodicy that is intelligible and plausible to us, God deserves our contempt, not our devotion; and the Argument from Design fails to show that a good and worshipful God designed our universe.

\section{ii. A Process Theodicy that Works}

Its handling of the problem of evil is one of the greatest strengths of Process Theism; and we will next explore the key elements in its highly credible theodicy. No one consideration can solve the problem of theodicy all by itself, so the cumulative weight of all of the following pieces of the puzzle must be considered. A credible theodicy must incorporate a. The Free Will Defense, b. The Soul-Making Defense, $c$. The Utility of Law and Order, $d$. The Conflict of Good with Good, e. Consolation, and perhaps f. Compensation.

\section{a. The Free Will Defense}

If evil decisions originate with free creatures within the world rather than with God, then God is not responsible for them. Being responsible for a choice and its consequences means originating that choice knowingly. A free and responsible choice originates with the intelligent moral agent who makes it. If, as Classical Theism affirms, God, the sole originative cause of all things, predetermined all choices ever made by created moral agents, then God is responsible for them. Human moral agents who deliberately inflict unspeakable harms on others do not originate their own malicious decisions if God programs and predestines every human choice from eternity.

Jonathan Edwards argued that all human choices are determined by our strongest desires or sets of cooperating desires, which, in turn, are ultimately caused by God. Being responsible and blameworthy, he said, means merely that a choice is evil and that the desire to do evil predominates; but the origin of the choice is irrelevant, he contended. Other Classical Theists appealed, inconsistently, to the free will defense, while clinging to the belief that God plans, foreknows, and foreordains everything.

Believers in free will, including Process Theologians, think that the question of the origin of our choices is highly relevant. Moral agents are responsible only for choices that they originate. Because our choices are originative or creative, the free will defense partly solves the problem of theodicy. Our choices 
would not originate with us if they originate with a God who programs them into us from eternity. What greater evil could a Malevolent Demon inflict upon us than to make us incapable of choosing to be virtuous or to do what is right, and then to punish us with Hell's infinite agonies for being and doing exactly as he created us? How better could we conceive of a Malicious Demon?

Process Theology says that finite agents are responsible co-creators with God. We originate our own free decisions. God is not the only existing creative or originative agent. When we freely choose to inflict evil on others, we are responsible, not God. Events in the world, including the human psyche, are influenced but not completely determined by the past. As free agents, we are partly created, partly self-creative. God makes relevant possibilities for choice available to us; but we freely select among them. Efficient causation consists of necessary but not sufficient conditions that partly structure present moments of partial self-creativity at the quantum level and in human and animal consciousness. All relatively complex created individuals are co-creative with God.

But why did God not predestine all creatures always to choose and do what is right, never what is wrong? Why did God not create the Kingdom of God in all its glory from day one? The free will defense answers that freedom is worth the price of its potential and actual abuse, and that without the potential to choose either good or evil we would not be free. Free creatures, by definition, may choose to do wrong as well as right; creating or originating our own choices between right and wrong is the paradigm instance of freedom.

Well, if freedom is so valuable that its availability outweighs the potential for its misuse, why did God not create us so that we always freely choose the right and the good? The answer is that this very notion is incoherent, like the idea of a round square. A Divine Reality who originates all choices must originate and pre-determine all creaturely choices to do what is right (or wrong). Creatures would not have a free and unconstrained choice between right or wrong if they are utterly constrained from eternity always to choose rightly and could not choose otherwise. The claim that God could cause free and originative creatures always to choose what is right just makes no sense. All free choices could have been otherwise.

Mainstream Process Theologians, we saw earlier, claim that God could not create unfree creatures who necessarily do what is right because being any kind of a concrete individual at all involves creative freedom. Creativity is a universal metaphysical category. Just as quantum events cannot exist at all at less than Planck dimensions, so it is impossible for any concrete events to exist at all unless their becoming is partly indeterminate and self-creative, says traditional Process Theism. The Divine self-limitation view, by contrast, affirms the widespread prevalence of creativity, even if it is not absolutely universal, because of the value of creativity itself, not because of its metaphysical necessity. Indeterminations, if not creativity, at lower levels of physical and biophysical organization is a necessary condition for freedom at higher levels. At the very lowest 
level of quantum events, creativity is minimal if not non-existent much of the time; but from the lowest to the highest level of physical reality, quantum physics is radically incompatible with rigid determinism. Quantum indeterminacy makes room for creative freedom at higher or more valuable and complex levels of biological and psychological organization. Even at the level of the most primitive individuals, the universe is always slightly out of control, including Divine control. Quantum level realities behave spontaneously and unpredictably occasionally. At higher levels of integration, absolute Divine control is completely out of the question. Creation is risky business, even for God.

Even the course of evolution always was and will always be slightly out of Divine control. Free decisions made by God and by living creatures, and indeterminateness in subatomic and atomic level quantum flukes, influenced the flourishing, survival, and evolution of all living things, including human beings. God was not the only decisionmaker directing and contributing to human evolution. We were created in part by God and in part by the free decisions made by all our pre-human ancestors throughout billions of years. If some of our progenitors had made different decisions, some species resembling us or our hominid ancestors, but not necessarily homo sapiens, might have resulted and prevailed. Given the power that modern medicine has given us to control and reorder genetic blueprints transmitted to future generations, we can now significantly influence the future course of evolution. Will we use this knowledge and power wisely? Not even God knows the answer!

The free will defense is possible only in a slightly wild and unpredictable universe. If the world is slightly untamed, out of control, and unpredictable at every level of actuality, the free will defense has some bearing upon the problem of natural evil as well as moral evil. The free will defense is usually applied only to evils caused by moral agents, not to evils caused by natural processes. Process Theologians repudiate this limitation. If creativity or at least indeterminacy belongs to every actual entity, then God cannot and does not absolutely control everything, including those natural processes that are hostile to living beings and their projects. Natural disasters like earthquakes, hurricanes, tornadoes, droughts, and diseases result partly from the operation of natural laws and partly from the inherently unpredictable and uncontrollable-by-others selfcreativity and/or indeterminacy of all physical and biological events, including those at quantum levels of physical reality.

Quantum physics definitely rules out Classical Theology's concepts of both Divine omnipotence as absolute control, and Divine omniscience as knowledge of every minute detail of the entire past, present, and future of the universe all at once, for such definiteness about the self-creating present and the uncreated future is just not there to be known. God does not have the knowledge and will not use his power to prevent all evils, natural or otherwise, because God, by voluntary self-limitation, is not the sole originative agent functioning in the universe. 


\section{b. The Soul-Making Defense}

Many desirable human traits of character would never develop in a world without evil. John Hick stresses the soul-making defense, according to which evil is necessary as a means to moral and spiritual development. ${ }^{32}$ Process Theology can easily incorporate this as an important element in a workable theodicy, but not the sole element.

All human beings start very low (a single fertilized ovum) on the scale of intellectual, moral, spiritual, and personal development. Newborn infants begin their lives in relative ignorance, innocence, and impotence, as Adam did in the Genesis creation myth. Because evolution is true, the biblical Adam and Eve never really existed; but we all begin our lives as little Adams or Eves. Initially, as infants, we do not know the difference between good and evil, right and wrong, even if a predisposition is there. Our intellectual, moral, spiritual, and personal potentials develop and mature only within supportive social and physical environments. Their development also requires individual creative effort in response to real and dangerous challenges.

Adversity really is a necessary condition for the development of many highly desirable traits of character and moral and spiritual virtues. Without real evils, real dangers, we could never develop courage. Without scarcity, hardship, and suffering, we could never become generous, self-sacrificing, patient, kind, and compassionate. Without real and constant threats to happiness, security, and those we love, including ourselves, we would never develop moral conscientiousness and responsibility. Without frailty and death, we would never be able to appreciate strength, health, and life itself. The existence of evil is a necessary condition for the realization of many soul-making goods.

The soul-making defense may be carried too far; its scope is definitely limited. It solves part of the problem of evil but not all of it by a long shot. John Hick, its principal patron in our time, is well aware of this. Some attempts to make it work are very implausible.

Some theologians argue that without evil, there could be no good at all; correspondingly, without goodness, there would be no evil at all. If this were true, Heaven, lacking all evil, could not be good; and Hell, lacking all goodness, could not be evil. Even Heaven might be a challenging place to live!

Unless good and evil co-exist in a complementary relationship, it is often said, we would not be able to recognize either one, for contrast is essential for recognition. Without evil, the argument goes, we could not recognize goodness; without pain, we could not recognize pleasure, a significant ingredient in human happiness. But this is not true. There are degrees of pleasure; and contrasts between high and low degrees of it would be quite sufficient for recognition purposes; so would the contrast between any given degree of pleasure and a neutral state of consciousness that is neither pleasurable nor painful. Pleasure definitely could be recognized and appreciated in a world without pain, so the 
reality of pain cannot be justified merely because it is essential for the recognition of pleasure or happiness. However, pain has other constructive uses.

Pain has tremendous survival value. By alerting organisms to danger, it often prevents much greater injury or harm. Its presence in the world has considerable justification. Thomas H. Huxley, following Alfred Lord Tennyson, characterized the world of nature as "red in tooth and claw;" but many of the horrors of the "struggle for existence" may be greatly exaggerated.

In the wild world of non-human animals, much less pain and struggle, and much more joy, empathy, and cooperation, exist than we often suppose. Many of the cooperative and self-sacrificial features of human morality may be found also in the non-human animal world ${ }^{33}$ but non-human animals can foresee relatively little of what is to come and do not suffer greatly from the anxieties about the future that trouble members of our species with more foresight.

Most living species and individuals are plants, and so are most things that are killed and eaten for food. As Mary Midgley indicates, "In fact, nature is green long before she is red, and must be green on a very large scale indeed to provide a context for redness. ${ }^{34}$ Most animals, both individuals and species, including the dinosaurs, were and are plant-eating herbivores, not carnivores or omnivores who consume the flesh of other living creatures. Carnivores, dinosaurs included, have a vital role in maintaining ecological balance and the vigor and zest of individuals and species, as does death itself. Much of the animal pain that we imagine to be involved in being killed and eaten by predacious carnivores is actually suppressed by endorphins and other natural analgesics secreted during the chase and attack, especially when predators kill quickly. Unfortunately, they do not always kill quickly; and we do not know how long a dying animal can benefit from "stress induced analgesia." 35

Pain is genuinely troublesome for theodicy because all too often its intensity and duration are way out of proportion to its usefulness for soul-making or any other rational purposes. Agonizing bodily pain and mental anguish suffered while dying from cancer and many other diseases and injuries often do not correlate with valuable practical or spiritual lessons learned from suffering or with virtues developed by enduring anguish. All too often, both human and subhuman animals are simply and speedily crushed by overwhelming adversity, and they neither learn from it nor grow in moral and spiritual character as a consequence of it. God cannot and does not always bring from evil the sort of good that we would like to see. Tragedy and loss are very real in our universe.

Clearly, despite its importance, the soul-making defense alone does not resolve all the problems of theodicy. Too many individuals suffer and perish with little or no opportunity for soul-making, even if on the whole the worldsystem tends toward the best. In many instances, soul-making is a good brought forth from evil; but all too often it does not happen. If the God who designed and made our world-system is to be regarded as worthy of worship, the soulmaking defense must be bolstered by further considerations. 


\section{c. The Utility of Law and Order}

Many very real evils cannot be explained and justified by the free will and soul making defenses. Premature deaths, grave incapacitations, and grievous sufferings that serve no legitimate purposes of the sufferer appear to be pointless evils; but are they entirely pointless in the great scheme of things? Some great good other than soul-making might justify the existence of many seemingly pointless evils.

The immense usefulness and practical value of natural law and order resolves many of the remaining difficulties. Laws of physics, chemistry, biology, sociology, history, and psychology are neutral to good and evil in the sense that they are necessary conditions for both. Beneficial sunshine and rain fall upon the just and the unjust alike; so do harmful diseases and other natural adversities. The same natural laws are in effect no matter what.

A category mistake is made when moral categories like "unjust" or "unfair" are applied to the undesirable effects of the workings of natural laws and processes. When bad things happen naturally to good people, only non-moral categories like "tragedy" or "misfortune" are appropriate. Tragedies do not call the moral goodness of God into question. Ours would be a strange world, indeed an impossible world, if one set of physical or natural laws were operative for righteous people and another set for the wicked.

On the whole, natural laws and all the initial components of our lifesupporting universe are more beneficial than harmful. Without them, we would not be here at all. Individuals who master the laws of nature and learn how to use them can, within broad limits, control their own destinies and greatly improve their chances for having a good life relatively free from suffering, incapacitation, deformity, and premature death. Informed individuals may use the laws of nature to enrich their lives by cultivating happiness, adventure, beauty, virtue, and other consciousness-enriching goods in effective ways.

Many life, health, and happiness enhancing behaviors are wired into nonhuman animals as instinctive responses to environmental conditions; and, to our great benefit, we human beings can learn the laws of nature and adjust our activities accordingly. Laws of nature can and do work for us rather than against us most of the time, but not always.

Steven Weinberg complains that we will find no evidence of a God who cares for life, intelligence, morality and beauty in the laws of nature because "The God of the birds and trees would have to be also the God of birth defects and cancer." ${ }^{36}$ But what else would one expect from a wise and benevolent Deity? How otherwise should God have created the world? How could and should the order of nature be different? Be specific! If the laws of nature were changed very much, no life would be possible. It is very doubtful that either we or God could create a significantly better world if we tried. Birds, trees, birth defects, and cancers all exemplify the same basic laws of nature. 
Should an intelligent, powerful, and benevolent Deity suspend the laws of nature to prevent harm to beloved creatures when natural laws work against them? Some Theists believe that God occasionally works miracles for such purposes. Miracles result, by definition, from an influx of transcendent energy or efficient causation that temporarily interrupts, suspends, or redirects existing laws of physics and chemistry. For the sake of the argument, let us assume that miracles can happen, sometimes, perhaps, in response to prayer. Why then does God not work many, many, more miracles to prevent much more pointless suffering, incapacitation, deformity, and premature death? Loving parents would protect their children from these ills if they had the knowledge and power; so why does a God who is supposed to be much more loving, powerful, and knowledgeable not do as much?

The answer, in part, is that a lawful and orderly environment, one that loving human parents are in no position to change, is itself a very great instrumental good; and the dependability of nature is worth the price of most if not all evils that result from the orderly workings and habituated activities of concrete entities. We abstract and generalize these regularities into natural laws. The advantages of natural laws or regularities clearly outweigh their disadvantages most of the time, but not always. So why aren't they occasionally suspended?

If we knew that we could expect God to solve all our problems for us and save us miraculously every time we get into a jam, we would never develop into conscientious and responsible persons. People who expect too many miracles are usually not very responsible individuals! Soul making reenters the picture unexpectedly at this point. The laws of nature enable and promote it. Even nonhuman animals who learn and generalize from experience, as most do, would not learn and grow in their own more limited yet significant ways if miracles were commonplace.

To announce God's presence and concern, miracles may happen occasionally. Another process heresy! If they do they are exceedingly rare; and we cannot count on them. If miracles were so frequent that we could predict and rely upon them to deliver us from all evils, then they would be the laws of nature, and we would assume that they had natural causes! Natural laws just are the regularities that we can count on and predict. But little or no soul-making would exist in a world where miracles were laws of nature.

\section{d. The Conflict of Good with Good}

Process Theologians point out that much seemingly pointless evil actually results from the conflict of good with good in a pluralistic universe, one that contains a significant number and variety of living beings, where legitimate interests are bound to conflict. No moral evil is involved when legitimate interests are pursued at the expense of others, but tragic non-moral evils may result. 
Our world manifests many examples of the conflict of good with good. When two people apply for the same job, both cannot have it; but the winner normally does nothing immoral in taking it at the loser's expense. A violent death for a wildebeest or gazelle provides food for lions, cheetahs, wild dogs, and their young. They would otherwise die painfully of starvation. Seeming inefficiency, waste, and death for some means vibrant life for others. All individuals must die eventually to allow room and resources for others to live. Organic matter is never wasted; in the struggle for life, evil is transformed into redeeming, sacramental goodness.

Holmes Rolston, $\mathrm{III}^{37}$ and M. A. Corey ${ }^{38}$ forcefully developed the thesis that the apparent randomness, wastefulness, and inefficiency of the evolutionary process is actually God's deliberate rational strategy for assuring species survival, adaptability, and complexity under environmental conditions that are likely to change drastically over the course of time. A creator God who cherishes biodiversity must consider the design and well-being of vast unfolding ecosystems within which individuals and species exist and interrelate, as well as the design and well-being of the individuals and species themselves. At a systems level, earth's ecosystems, where one individual's loss is always another's gain and nothing is ever wasted, are remarkably efficient and wellordered. They are models of rational foresight and planning.

Still, individual losers in the conflict of good with good can be greatly frustrated and disturbed; some suffer unbearably; and many perish prematurely. Grief is commonplace over losses in love, athletics, business, the struggle for life, and every legitimate competitive interest. Painful conflicts, serious frustrations, deep disappointments, unbearable sufferings, irrevocable losses, and premature deaths are inevitable in an orderly world containing a great diversity of consciously active and creative individuals. This is the price that must be paid for richness, diversity, freedom, and creativity.

Conflicts of good with good may also evoke positive virtues like wisdom, patience, resoluteness, inventiveness, heroism, and sacrifice. The immense worth and extent of both human and non-human cooperation, ingenuity, fortitude, and voluntary self-sacrifice should not be underestimated. Fortunately, shared interests do not always conflict; and innovative strategies for minimizing conflict are often available.

Could God, should God, do anything to prevent evils resulting from the conflict of good with good? Not if the price is too high. What exactly would God have to do? Eliminating all or most conflict of good with good would necessitate either abolishing or preventing the existence of great numbers of active individuals, or else significantly diminishing their creative power or freedom. If the existence of many and diverse individual centers of conscious experience, creative activity, and valuation has sufficiently great worth, lesser evils resulting from the conflict of good with good are justified. 
God does not deliberately cause every bad thing that happens to good people; in this sense, evils are no part of God's grand plan. But God always aspires and tries to bring as much good out of evil as possible, so there is this much truth to the common belief that everything is a part of God's plan. God always plans to bring good out of evil! For example, mad cow disease is a horrible thing for its animal and human victims; but great good may come from it in the long run. It may be one of the best things that ever happened to further vegetarianism! God may use this horrible disease to inspire us rethink the exploitative destructiveness of our relations with other living things and our environment as a whole, when otherwise we would be oblivious.

Theodicy requires an ideal balance between divine and creaturely power. A loss of desirable creaturely power correlates with every increase in desirable divine power and control; and every increase in creaturely power must be accompanied by diminished divine power and control. To empower his creatures, God voluntarily limits his own power by divine choice. Every desirable reduction in conflicts between individuals would require undesirable decreases in the number, variety, intensity, zest, vigor, virtue, and creativity of creatures, as well as radical and inefficient modifications of the inclusive ecosystems that support them. All good things have their price. If we were God choosing a design for a good world as complex as our own, could we do any better? That we could is very doubtful.

\section{e. Consolation}

In Process Theology, God is "The great companion-the fellow-sufferer who understands," as Whitehead put it. ${ }^{39}$ The profound conviction that an all-compassionate God genuinely understands and suffers with all creaturely suffering and loss gives great consolation in times of sorrow and woe. The God of Process Theology literally suffers with all who suffer; and Jesus on the cross is the supreme historical symbol of this. All evils inflicted upon all sentient creatures are ultimately inflicted upon God, who endlessly bears all suffering, loss, and every creature's cross so that an orderly world can be rich in intrinsically valuable, creative, responsive, and responsible individuals.

In Classical Theism, all forms of feeling are judged to be unworthy of God, even the highly desirable feelings necessarily involved in love, mercy, empathy, and compassion. God loves without feeling, is merciful without passion, and has compassion without pity, said the Classical Theologians. Kant considered any love composed even partly of feelings to be "pathological."

To the contrary, total affective insensitivity robs love, mercy, empathy, and compassion of most of their meaning and significance. Yes, cognitive elements are present in love, mercy, empathy, and compassion; but mere cognition is not enough. Divine attributes of immutability and impassivity betoken emotional insensitivity and moral impoverishment; but God truly bears our burdens. 
Classical Theism actually affords no deep religious consolation for evils suffered because in himself God is really not compassionate, as St. Anselm forthrightly acknowledged. God's works make it appear that he is compassionate, but he really isn't! For Classical Theism, the discrepancy between divine appearance and divine reality is absolute. In Process Theism, by contrast, desirable kinds of feeling are perfections; stony immobility is an imperfection; and God quite literally suffers with all who suffer. God cares deeply, fully understands, empathizes with, and is all compassion, pure unbounded love. God bears all our sorrows and griefs. In that insight is deep comfort and consolation.

\section{f. Compensation}

Do the elements of theodicy presented thus far really succeed in reconciling belief in an immensely knowledgeable, powerful, caring, and worshipful God with the hard facts of evil in the world? There is still room for honest doubt. Many individuals, human and non-human, are crushed by the evil of overwhelming suffering. Others are profoundly retarded or irreversibly comatose from birth. Others are gravely incapacitated or struck down as infants, children, or in the prime of life. Many die so prematurely that they have little or no chance for a worthwhile life or for any soul-making experiences, efforts, and adventures. If a sadistic maniac entertains himself by shooting a tiny baby to death before the eyes of its mother, the poor infant has little or no opportunity for happiness, spontaneous creativity, self-development, and soul-making. How could a good, powerful, and benevolent God allow such things to happen? How could everything that happens be a direct expression of the will of God, as Classical Theists claim? Do we never fail to do God's will, not even when we perpetrate unthinkable atrocities like the Holocaust?

In this world, evils suffered pointlessly are sometimes compensated. Theologians like John Hick hold that God will eventually compensate unfortunate individuals for their tragic sufferings and losses in a better life to come. Heaven will make all things right in the sweet by and by. Hick's book, Death and Eternal Life, ${ }^{40}$ defends this theological perspective in depth and effectively replies to philosophical charges that the idea of survival after death is empirically meaningless or nonsensical.

Hick shows that the idea of compensation after death for evils suffered in this world makes sense, at least to the extent that we can imagine experiences that would verify survival after death, but not in the sense that we now have experiential access to other worlds. Hick argues convincingly that compensation in a life after this life would go very far toward solving all the residual problems of theodicy. However, sensitive rebels like Dostoyevsky's Ivan Karamazov may want no part of such an "eternal harmony." By the time we reach the end of Hick's book, we discover that he provides no evidence whatsoever that other 
worlds exist or that we survive within them after death. Intelligibility is not equivalent to knowledge and truth, even if it is a first requisite.

Actual evidence for survival after death in another world is indecisive but not totally nonexistent. The transcendent spacetime of Heaven is vulnerable to the same objections previously raised against world-ensemble cosmologies. We have neither direct observational nor indirect inductive evidence for other worlds, including Heaven, antecedent universes, or contemporary bubble universes. If Heaven exists, we could never know it rationally in this life. Yes, a compensatory Heaven is logically possible; but this concedes only that the concept is intelligible and free from logical self-contradiction.

Compensation theodicy resolves residual problems of evil in this world by appealing to worlds about which we now know nothing; but a successful Teleological Argument requires that an adequate solution to the problem of evil be based upon the observed order of this world alone. It contends that the order of our world implies an intelligent and beneficent world designer. If the problem of theodicy cannot be solved by reference only to the discerned design of our universe, the Teleological Argument fails, for it aspires to infer God's existence from the observed order of our world. Uncompensated evils permitted by the observed order of this world may (or many not) be incompatible with the existence of a supercosmic, benevolent, and intelligent God. We do not know with certainty.

This author believes that elements a. through e. in the preceding discussion are sufficient to resolve the problem of theodicy; but if they fail, the Teleological Argument is not successful. Whether any theodicy succeeds or fails depends on fallible and variable human judgments that weigh existing goods against existing evils. People who sincerely want to be rational about such immense complexities and uncertainties must often just agree to disagree without questioning one another's integrity.

We have no knowledge of or control over what happens to us after death. At that point, everything is in the hands of God. We have no legitimate claim to anything more, but God's love may give us more than we deserve. There may or may not be compensatory survival after death, just as Quantum Cosmology's many worlds may or may not exist in Divine Superspacetime. We cannot know such things now, even if they are so. Theistic religions usually teach compensatory survival after death; faith often affirms it; but rational evidence for individual survival after death is presently inconclusive. If God chooses to give it, there could be ultimate compensatory justice; but about this we now have no sufficient rational knowledge.

Evil in the world menaces the Teleological Argument for the existence of God; but even without postmortem compensation, the threat is significantly abated by the collective weight of the free will defense, the soul-making defense, the usefulness of natural law and order, the inevitability of the conflict of good with good in a pluralistic universe, and the consolation of Divine 
compassion. Compensation for evils suffered may or may not be operative in some Other World. About that we really do not know; but we can hope. 